\title{
A thermally stable tension meter for atmospheric soundings using kites
}

Article

Accepted Version

Harrison, R. G. and Walesby, K. T. (2010) A thermally stable tension meter for atmospheric soundings using kites. Review of Scientific Instruments, 81 (7). 076104. ISSN 1089-7623 doi: https://doi.org/10.1063/1.3465560 Available at https://centaur.reading.ac.uk/6113/

It is advisable to refer to the publisher's version if you intend to cite from the work. See Guidance on citing.

Published version at: http://link.aip.org/link/?RSI/81/076104

To link to this article DOI: http://dx.doi.org/10.1063/1.3465560

Publisher: AIP

All outputs in CentAUR are protected by Intellectual Property Rights law, including copyright law. Copyright and IPR is retained by the creators or other copyright holders. Terms and conditions for use of this material are defined in the End User Agreement.

\section{www.reading.ac.uk/centaur}

\section{CentAUR}

Central Archive at the University of Reading

Reading's research outputs online 


\author{
A thermally-stable tension meter for atmospheric soundings using kites \\ K. T. Walesby ${ }^{*}$ and R. G. Harrison** \\ Department of Meteorology, University of Reading, \\ P.O. Box 243, Earley Gate, Reading, Berkshire RG6 6BB UK.
}

accepted for publication in Review of Scientific Instruments

\begin{abstract}
Kites offer considerable potential as wind speed sensors - a role distinct from their traditional use as instrument-carrying platforms. In the sensor role, wind speed is measured by kite-line tension. A kite tether line tension meter is described here, using strain gauges mounted on an aluminium ring, in a Wheatstone bridge electronic circuit. It exhibits a linear response to tension $\left(19.5 \mathrm{mV} \mathrm{N}^{-1}\right)$ with good thermal stability (mean drift of $-0.18 \mathrm{~N}^{\circ} \mathrm{C}^{-1}$ over $5-45^{\circ} \mathrm{C}$ temperature range), and a rapid time response $(0.2 \mathrm{~s}$ or better). Field comparisons of tether line tension for a Rokkaku kite with a fixed tower sonic anemometer show an approximately linear tension - wind speed relationship over the range $1 \mathrm{~ms}^{-1}$ to $6 \mathrm{~ms}^{-1}$.
\end{abstract}

\footnotetext{
* Now at: School of Engineering, Computing and Mathematics, University of Exeter, Devon EX4 4QF UK

** Corresponding author, email r.g.harrison@reading.ac.uk
} 
Kites have been used in meteorological research for around 250 years and have provided some of the earliest atmospheric measurements aloft ${ }^{1}$. Most studies deployed kites as aerial instrument platforms or "skyhooks". More recently, use of the kite itself as a sensor has become popular ${ }^{2}$. For example, the Tethered Aerodynamically Lifting Anemometer $(\text { TALA })^{3}$ monitored line tension and elevation angle electronically in order to infer wind speed. However, TALA systems showed sufficient thermal drift to require pre- and postflight corrections ${ }^{4,5}$. Here a thermally stable tension meter is described to improve kite tether line tension measurements for kites used as sensors.

The wind force on a tethered sensor kite can be approximated for wind flow normal to a flat plate ${ }^{6}$ as

$$
F=\frac{1}{2} C_{R} \rho A V^{2}
$$

where $F$ is the force transmitted down the kite tether to the ground anchor, $C_{\mathrm{R}}$ is the reaction coefficient (magnitude $\sim 1$ ), $\rho$ the air density, $A$ the kite area and $V$ the wind velocity. (Although $\rho$ is temperature dependent, the variation over the expected lower atmosphere range will be small.) In practice, equation (1) will not be exactly adhered to as kites do not fly at a constant angle of attack and continually deform under wind pressure. This equation was used to establish a design specification for the tension meter, showing a dynamic range to at least $100 \mathrm{~N}$ is needed for wind speeds up to about $10 \mathrm{~ms}^{-1}$, assuming a maximum typical effective kite area of $2 \mathrm{~m}^{2}$. A resolution of $2.5 \mathrm{~N}$ or better was required, and, as the kite sensor is expected to be particularly useful for investigating turbulence, an exponential time response of $0.3 \mathrm{~s}$ or better was sought.

Strain gauges were used to measure the kite line tension, by measuring the deformation of a ring carrying the tension of the kite line, to which the strain gauges were bonded. The strain gauges selected (RS Components 632-180 5mm aluminium gauge) had a $3 \%$ operational distortion limit, hence the ring was constructed from aluminium, to a design which restricted the maximum deformation. Initial testing showed the response was greater under gentle bending than pulling. The final design therefore employed an array of four strain gauges arranged around a circular aluminium ring forming the sensor head (Figure 1), with the strain gauges precisely opposite each other around the axis of the ring. Under tension, the sensor head elongates, causing deformation locally at each straingauge. 


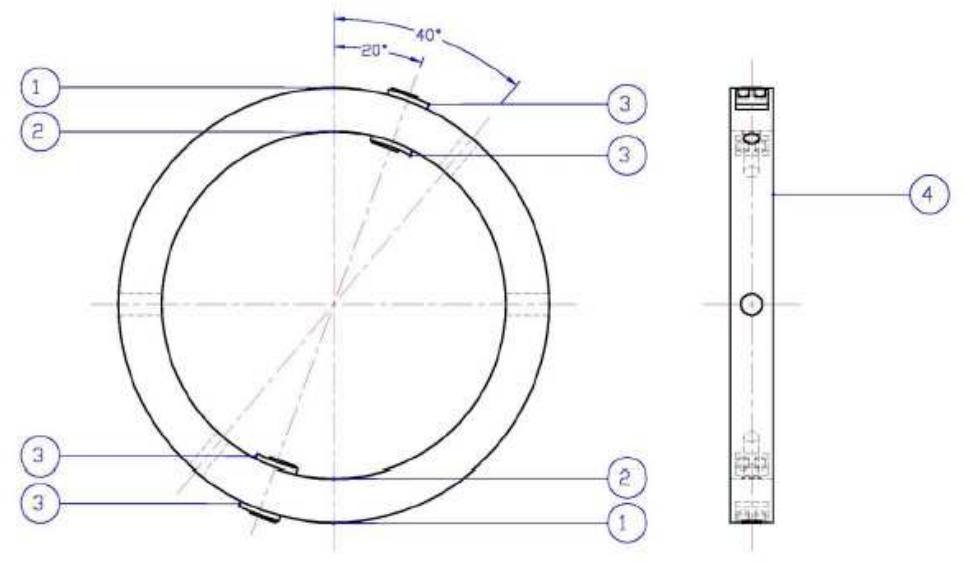

FIGURE 1 Design of sensing ring (diameter $80 \mathrm{~mm}$ and thickness $10 \mathrm{~mm}$ ), with outer (1) and inner (2) surfaces marked. (3) denotes position of strain-gauges on the outer surface and (4) shows the sensing head edge on.

Figure 2 shows the schematic of the electronic signal processing used. The set of four resistive strain gauges are connected in a Wheatstone bridge circuit, excited by a $9 \mathrm{~V}$ regulated supply derived from a $12 \mathrm{~V}$ gel cell. Using multiple strain gauges both improves the sensitivity over that of a single strain-gauge, and, because of the circuit's symmetry, it minimises the thermal drift for well-matched strain-gauges. The voltage difference from the bridge circuit is extracted by a differential stage (IC1), and amplified by a gain stage (IC2). This circuit was derived from a microvolt differential amplifier designed for small temperature drift $^{7}$.

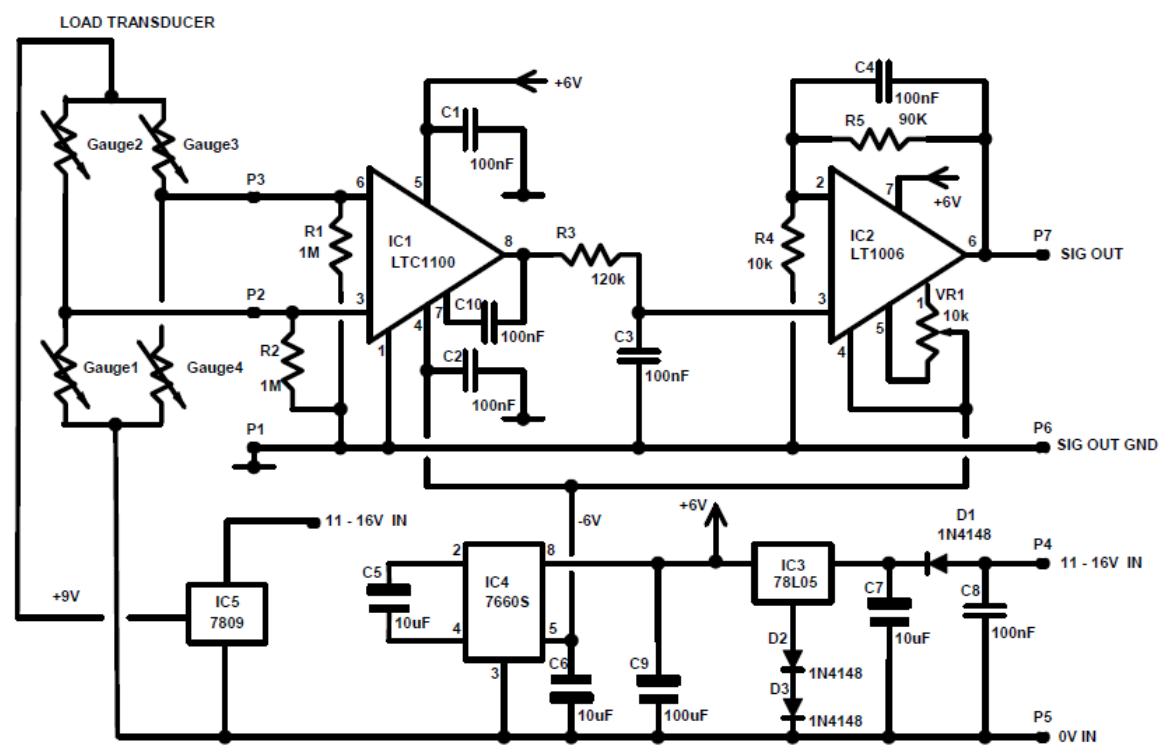

FIGURE 2 Schematic of the signal conditioning circuitry, with component values and part numbers marked. The four resistive strain-gauges mounted on the sensor head form a Wheatstone bridge arrangement. 
The tension meter was calibrated for forces in the range $0-100 \mathrm{~N}$ as predicted from equation (1), using a variable load. Figure 3(a) illustrates the linear relationship having gradient $(19.5 \pm 0.2) \mathrm{mV} \mathrm{N}^{-1}$ over the entire tension range, but showing a small negative offset $(\sim 40 \mathrm{mV})$ with no force applied. Three possible explanations were identified for this, all concerned with mechanical or electronic asymmetry. Firstly, slight differences in the amount of adhesive attaching each gauge to the sensor head could cause small differences in gauge curvature. Secondly, as the adhesive's thermal conductivity differed between the gauge and the aluminium, when combined with the differences in adhesive amounts this may produce different time lags for the gauges to equilibrate with temperature fluctuations in the aluminium ring. A third possible source of offset could arise from light differences in the electrical connections for each strain-gauge, such as from unequal wire lengths.

(a)

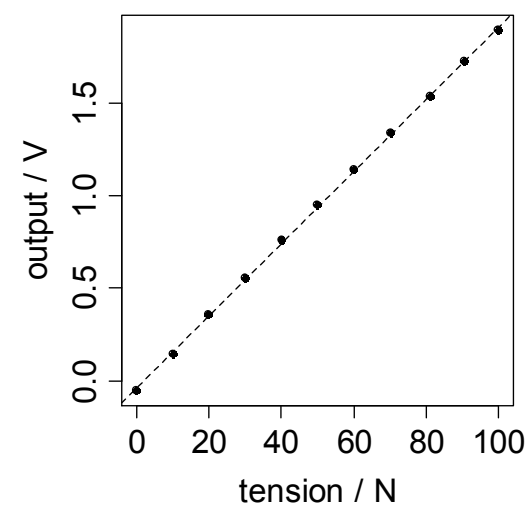

(b)

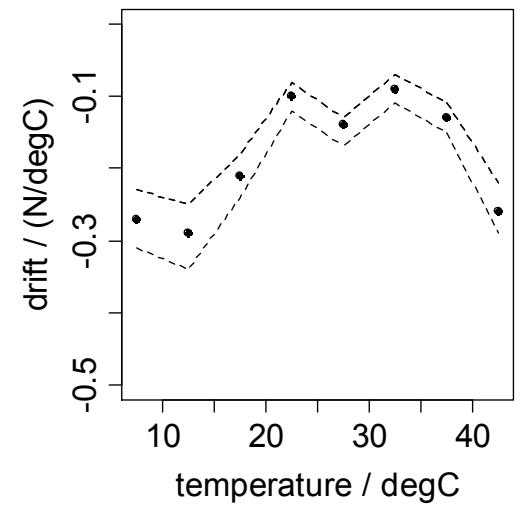

FIGURE 3 (a) Variation of the output voltage of the instrument for a range of applied tensions. (b) Temperature variation of output voltage expressed in terms of equivalent tension. Each point represents the drift over $\pm 2.5^{\circ} \mathrm{C}$ around the temperature considered, and the dashed lines show the extremes of the variations found.

Thermal sensitivity of the system was investigated in a temperature-controlled environmental chamber (Design Environmental model Delta 190H). The sensitivity to applied tensions was determined at temperatures from $5^{\circ} \mathrm{C}$ to $45^{\circ} \mathrm{C}$, limited by practical constraints within the chamber to $40 \mathrm{~N}$. A negative temperature coefficient was found, and 
the variation in sensitivity is shown in figure 3(b). The mean drift with temperature found was $-0.18 \mathrm{~N}^{\circ} \mathrm{C}^{-1}$ ( 5 to $45^{\circ} \mathrm{C}$ range). In field use with small tensions and temperature fluctuations generated by the passage of broken clouds, this drift can be used to apply a correction, by measuring the sensor head temperature. However when the thermal drift is less than $\sim 0.5 \mathrm{~N}$ during use, a temperature correction may not be necessary since such drift is comparable with the resolution.

The tension meter's frequency response was investigated by applying rapid tension changes. The sensing head was mounted solidly, with $0.5 \mathrm{~m}$ of kite-line attached; its output voltage response to step changes in tension was recorded using a chart recorder. Different weights of known magnitude were attached onto the kite-line by plastic cable ties, and step changes in tension generated by cutting the cable tie to release the weights in turn. Large $(85 \mathrm{~N} \rightarrow 10 \mathrm{~N})$ and small $(75 \mathrm{~N} \rightarrow 25 \mathrm{~N})$ tension changes were investigated and the exponential response time derived. In both cases, the time constant was $<0.2 \mathrm{~s}$ compared with the design requirement of $0.3 \mathrm{~s}$. The step changes in tension between $75 \mathrm{~N}$ to $25 \mathrm{~N}$ exhibited a damped oscillation of $\sim 10 \mathrm{~Hz}$ which decayed within $\sim 2 \mathrm{~s}$ : this was absent from $85 \mathrm{~N}$ to $10 \mathrm{~N}$ data. A supporting observation was that the weight remaining attached to the kite-line oscillated after the first mass was detached. For a body of $\Delta m$ added to a string already carrying a mass $m$, the new frequency $f+\Delta f$ of small amplitude oscillations is given by

$$
f+\Delta f=\frac{1}{2 \pi \sqrt{\frac{(m+\Delta m) l_{0}}{A Y}}}
$$

where $l_{0}$ is the length of the string under no tension, $A$ is the cross-sectional area of the string and $Y$ is Young's modulus ${ }^{8}$. Assuming $Y=117 \mathrm{GPa}$, equation (2) suggests that a step change in tension from $75 \mathrm{~N}$ to $25 \mathrm{~N}$ should result in oscillations of $\sim 9.6 \mathrm{~Hz}$, consistent with the observation.

Field experiments were carried out at the flat grass site of the University of Reading Atmospheric Observatory, surrounded by large trees and buildings. The sensing head was attached to a Rokkaku-type kite (flat area $2.3 \mathrm{~m}^{2}$ ) and the output voltage from the tension meter recorded with a miniature voltage logger (Tinytag Talk 2), at $1 \mathrm{~Hz}$ with $1 \mathrm{mV}$ resolution. The kite tension measurements were temperature corrected using the derived temperature sensitivity. A tower at the Observatory equipped with an ultrasonic anemometer (Gill Solent Windmaster) at $10 \mathrm{~m}$, was used for comparison with the kite measurements. Figure 4 shows the relationship between kite-line tension and wind speed (measured with the sonic anemometer). In the time series (figure 4a), both the tether line tension and wind speed datasets show similar structures, indicating that the kite responds to atmospheric flow variations. Figure $4 \mathrm{~b}$ shows the relationship of tether line tension with wind speed at $10 \mathrm{~m}$, which, for this kite, is approximately linear over the range $1 \mathrm{~ms}^{-1}$ to $6 \mathrm{~ms}^{-1}$, with sensitivity $1.54 \mathrm{Nm}^{-1} \mathrm{~s}$. 
These field measurements demonstrate that thermally stable tether line tension measurements can provide horizontal wind speed information through using a static kite as the sensor.

(a)

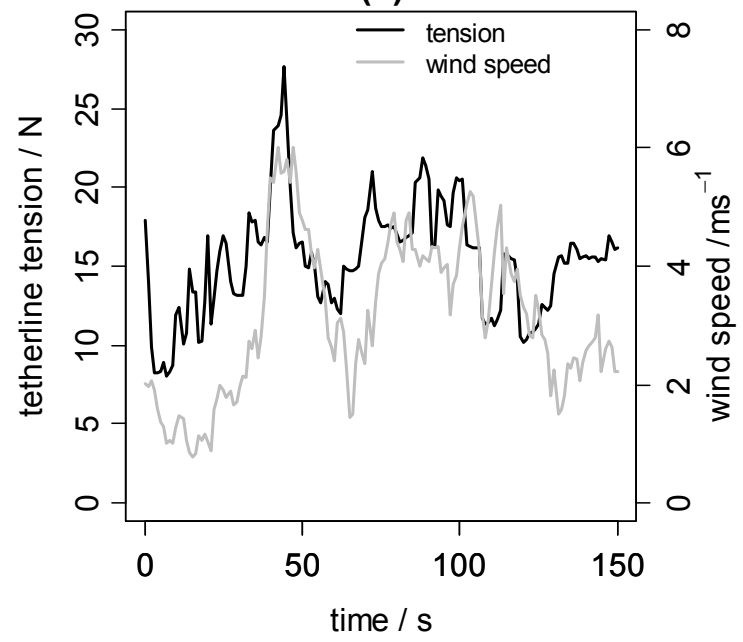

(b)

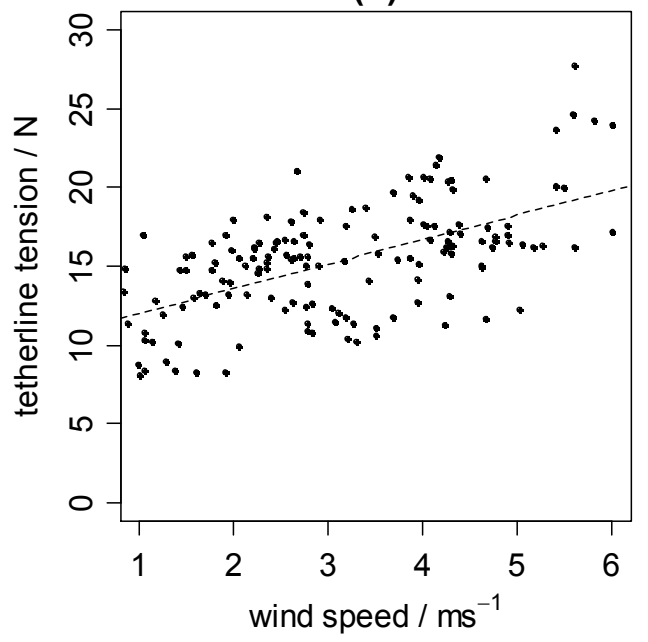

FIGURE 4 (a) Time series (1Hz samples) of kite tether line tension (black line) and horizontal wind speed at $10 \mathrm{~m}$ (grey line) for the kite flying at anemometer height. (b) Kite line tension against wind speed for the data in (a), with a least squares regression line added.

\section{ACKNOWLEDGEMENTS}

KTW acknowledges a studentship from the UK's Natural Environment Research Council. A.G. Lomas, S.D. Gill, R.J. Wilson and M.R. Stroud provided technical assistance.

\section{REFERENCES}

${ }^{1}$ D. Pelham, The Penguin Book of Kites (Penguin Book, London, 1976).

${ }^{2}$ G. Jenkins, Weather 36, 294-300 (1981)

${ }^{3}$ Approach Fish Inc. [No date] Instructions for Hand-Held Wind Measuring Device Clifton Forge, Virginia : Approach Fish Inc. 56pp.

${ }^{4}$ R. R. Baker et al, Wind Engineering 3, 2, 107-114 (1979)

${ }^{5}$ K. Kunkel, Evaluation of a tethered kite anemometer (US Army Electronics Research and Development Command, Atmospheric Sciences Laboratory, White Sands Missile Range, New Mexico, USA, 1981)

${ }^{6}$ J. C. Kaimal et al. The Boulder low-level intercomparison experiment (Report preprint No. 2, NOAA/NCAR Boulder, 1980)

${ }^{7}$ R. G. Harrison and J.R. Knight, Rev. Sci. Instrum. 77, 11, 116105 (2006)

${ }^{8}$ A. P. French, Vibrations and waves (Taylor and Francis, Cambridge, MA : 1971)

${ }^{9}$ M.J. Varley, Meteorol. Appl. 4, 2, 151-159 (1997) 